worker went further than this and tried to predict the 'communities' which might be expected to occur in (quantitatively) unknown faunas off the European coast.

By his use of the term 'community' Petersen seems to imply more than Hjort does, for example, in referring to 'societies' or communities of plankton forms in the different hydrographical regions of the Atlantic, or than botanists do in referring to ecological groups of plants, and by his relative neglect of soil analysis gives more importance to the mere association of animals than to the relation of the animals to the nature of the soil. In this attitude Petersen has in part followed Mobius, who long ago (I877) stated that the animals living on an oyster bed form a community, and goes on to say that "Science possesses, as yet, no word by which such a community of living beings may be designated.. where the sum of species and individuals, being mutually limited and selected under the average external conditions of life, have, by means of transmission, continued in possession of a certain definite territory. I propose the word Biocoenosis (from bios, life, and koinoein, to have something in common) for such a community."

Obviously all these are the beginnings of attempts in marine zoœcology or zoocönosis, and we are witnessing the early stages in the evolution of a nomenclature and, indeed, of method. Davis adopts, but unfortumately, we think, in a modified way, the Allen-Borley method of soil analysis, and pays insufficient attention to the hydrographical and topographical variants, which both Petersen and Borley noted. Thus in no case are all the correlated observations to date marshalled in such a way as to indicate an enduring natural classification of such associations or groups as do undoubtedly occur, although Petersen's broad method of treatment alone has certainly carried the problem beyond its initial stages. In his paper, Davis gives a remarkable table showing soil-analyses correlated with the animals inhabiting particular soils and clcarly shows that a large number of animals prefer a particular soil in the North Sea, though some are more catholic in habitat. The author concludes that animal associations were found, but that in detail those groups (communities) which Petersen found are not homogeneous in nature when regarded in relation to the soil analyses, nor strictly comparable with one another in the areas investigated.

We hold, however, that there is not enough information available for the latter part of the conclusion, since (I) Petersen gives no analysis of soils to define his communities, (2) the fauna in relation to known soils has not been adequately investigated at stations linking Petersen's scene of work with the North Sea stations, (3) Davis has himself grouped together animals only in relation to soils without consideration of other biological factors-despite Borley's warning -and (4) what is more important, the biological significance of the soil and medium for the animals inhabiting them has scarcely yet been considered, and a close study of individual species will be required to give the information needed on this point.

The trend of modern work is indeed to delimit and to come to grips with the problem of the relation of any animal to its habitat. The essence of the work on marine animal communities is the provision of a complete description of the factors of the habitat and the inter-relationships of the members, and the results should be stated so as to be capable of comparison or contrast with one another in all parts of the world.

J. H. O.

\section{Applied Psychology.}

PROF. J. MCKEEN CATTELL, the retiring president of the American Association for the Advancement of Science, gave in his address at Kansas City on "Some Psychological Experiments," a portion of which was published in NATURE of January 16 , an illuminating account of the development of the experimental study of individual differences. Starting with a description of the measurement of a simple sense reaction time, he proceeded to show, step by step, how the same type of objective measurement can be used in such a complicated action as the selection of a career.

Although no striking new experiments were described, Prof. Cattell's account of the recent applications of psychology was both original and stimulating. " Daily, weekly and seasonal curves," he says; " the optimum periods for definite tasks and for a day's work; industrial fatigue; temperature, ventilation and humidity; the most desirable sexual relations, food, amount and distribution of sleep ; rest, play and physical exercise; the use and misuse of emotional excitement and of drugs as sedatives and stimuli : these have been the subjects of many investigations. . . .

An interesting point discussed by Prof. Cattell is the variation of the curve of ease of learning with age. It is well known that a young child can learn to pronounce a foreign language more easily than can his father and mother. Three years is found to be the optimum age for acquiring pronunciation, and after the age of twelve years it can but rarely be learnt correctly. In the same way other abilities-both physical and mental-have their optimum learning curve at various ages. It is an important task for the educational psychologist to examine the practice curves of the ordinary school subjects at different age levels, so that he can suggest at what stage they should be commenced. Mathematical relations, Prof. Cattell finds, are generally taught a couple of years before the child's age allows him to respond to them with the least effort.

Reference is made to the work that is being done in England by the National Institute of Industrial Psychology to reduce industrial fatigue. Psychologists have found that by arranging for suitable alternative periods of rest and exercise, and by supplying training in the use of the most physiologically economical movements, it is possible to increase the output of the worker-be he miner, mill-hand, or typist-and simultaneously reduce his fatigue. Prof. Cattell outlines the cnormous economic importance of this work and describes how in America a Psychological Corporation has been formed to advance this new science, to allow of research, and to protect the interest of psychologists. "The Father of American Psychology," as Prof. Cattell is well named, is the president of this Corporation, and its establishment has already been amply justified. W. J. G. S.

\section{University and Educational Intelligence.}

Birmingham.-Dr. Daniel Hanson, principal assistant in the Metallurgy Department of the National Physical Laboratory, Teddington, has been appointed to the feeney chair of metallurgy, which will be vacated by Prof. T. Turner at the end of the current session.

Mr. J. Armitage Robertson has been appointed assistant lecturer in zoology.

LonDon.-The following doctorates have been conferred: D.Sc. (Chemistry): Mr. H. T. S. Britton (King's College and Imperial College-Royal College

NO. 2945 , VOL. II 7$]$ 